\title{
Methodology of an artistic work poetics of cinema analysis
}

\section{O. Bulbachinska}

\author{
Kyiv Boris Grinchenko University, Ukraine \\ Corresponding author. E-mail: olga23boeing@ukr.net
}

Paper received 27.01.20; Accepted for publication 12.02.20.

\section{https://doi.org/10.31174/SEND-Ph2020-217VIII65-02}

\begin{abstract}
The article makes sense of the concept of "poetics of cinema" helping to monitor writer's artistic thinking cinematographism. It outlines cinema and literature synthesis development status nowadays. The article proves the necessity of texts practical examining using a clear analysis methodology according to the point of view of cinematographism. It formulates poetics of cinema analysis methodology of writers' prose works. It also offers artistic works analysis algorithm with key images and shots separating, cinematographic means searching, film frames dividing, recourse, set-ups and rhythm examining, and images cinematographic montage techniques as decoding means for the whole work esthetic component.
\end{abstract}

Keywords: poetics of cinema, methodology, an algorithm, an image, means, a frame, a shot, recourse, a set-up, rhythm.

Introduction. In modern literature studies a systematic scientists' attention both to poetics of cinema of individual works and writers' cinematographic thinking are available.

The given problem is thought both in theoretical and historic-literary area. No doubt, such forced attention only confirms the theme actuality, caused by powerful artistic value potential attained by arts interpenetration.

The outstanding people previewing cinema issues are $\mathrm{L}$. Generaliuk, N. Gornytska, by G. Klochek, A. Pokulevska.

Body. The problem development status. The scientists indicate there is no uniform interpreting of literature and cinema interaction nowadays. In modern literature studies there is no uniform classic definition of "poetics of cinema"

As the researcher Pokulevska asserts, "the research emphasis is altered toward synthetic two arts interaction ( $N$. Gornytska, D. Nalyvaiko) and cinema elements functioning in literary works is left without due cognizance". [6; p.5]. Her opinion the scientist confirms by G. Klochek points of view on the problem given: "This problem novelty and perspective are still requiring the confirmation - not so declarative, but evidential, made both at theoretical, methodological and at practical levels - the former, practical level is especially important because it is known that there is no more reliable method to prove the rectitude of theoretical and methodological structures, tested by their practice, in this case - by a practical analysis of artisticliterary texts" $[6 ; \mathrm{p} .5]$.

The purpose of the article. Certainly, for practical artistic texts analysis a clearly articulated research methodology which is the purpose of this research is required.

Methodology. A prose work poetics of cinema analysis methodology will be based on tested literary analysis of artistic-literary texts and theoretical cinematography research.

In modern literature studies there is no constant definition of poetics of cinema. However, the attempt to underline this definition content and functions we find in S. Eisenstein's, M. Romm's works and modern literary scholars' research N. Gornytska, O. Punina. S. Eisenstein's asserted that poetics of cinema is a deep realizing of literary poetics and imagery laws requiring a professional analysis of all the literary forms [9].

Literary scholars' works survey shows that everyone chooses his/her own way for poetics of cinema research. We turn our attention on some examples to make the given thesis more concise. In particular, L. Gorbolis starts his analysis since the date of work writing in context of cinematography development. The next step is the work composition analysis with its every part rhythm images. While "the rhythm affects on the images dynamics" [3; p. 32], it determines the further order of precedence - images' world analysis. The textual analysis is becoming the main method nowadays. If the image appears in different frames, it is reasonably to speak on montage techniques. The image research requires the conversation about image presentation recourse and cinematographic techniques of its creating.

O. Braiko considers, that "in the particular works analysis it should take into consideration, that all the fragments montage doesn't neutralize their internal structure, where other visual image creating means and other image creating ones are available (recourse, frame designed depth, color, movement) but includes them in the chain of mutual comparisons, makes more expressive supplementing, contrast or conflict relationships between visualized compositions elements" [1; p. 27].

Results and discussion. The work at prose work's poetics of cinema research should start from separating its key images. It is caused by some reasons: first, A. Tarkovsky reasonably asserts, that "an opinion in the art doesn't exist beyond its figural expression, and a image exists as some perception of volitional reality created by an artist according to his/her abilities and worldview peculiarities" [8; p. 56]; secondly, separating a image in literature plays a leading role, as poetics of cinema role is realized through image creating system, where a visual representation is crucial. Through symbolism, plasticity, emotionality and infinity means artists obtain the whole artistic completeness. Using symbolism the recipient doesn't think trough shown images peculiarity, as he/she understands their symbolic identity in artistic world subconsciously" [8; p. 56];

In contrast to symbolism image plasticity consists in "life truthfulness, in factual concreteness" " [8; p. 76]. The author, showing a person, creates a image relevant to moment life fact and coincidences with the reality. Consequently, as A. Tarkovsky considers, such image is "free from symbolism and it is not a cinematographic one" [8; p. 77].

Image's emotionality and infinity interact closely. Image's emotionality helps the recipient to cover the image entirely, without a certain division for details, as "'it is impossible to pick out the detail from the context of the whole, to determine the best one impression moment and not 
the other, and to fix it for yourself ultimately - find some equilibrium in the attitude for a image" [8; p. 112]. The emotionality directs the recipient to a image infinity realizing. The artistic image immanent feature is its infinity, thanking to which the writer "places the work in relevant life contexts, connects it with certain sense formulas" [8; p.113].

Artist means and images creating techniques system is very wide and every artist possesses this arsenal in his/her own way, especially if he/she has a developed cinematographic thinking. Cinematographic means searching - the next step - should start by a clear distinction of literature and cinema features. Such way proposed by A. Tarkovsky seems reasonable. In the scientist's opinion, the own laws are typical for all the arts by which they are served since their origin and during their further development. The common feature of cinematography and literature is "incomparable freedom with which the artists have a possibility to handle with the material and organize it consequently" [8; p. 63]. Both a writer and a film director, having unlimited frames of reality perception, regard it according their own subjective observations.

However, sharing the scientist A. Tarkovsky's judgment, we consider that distinct features are more, as expression of things shown through the word and film adaptation requires different forms: "One can say that for the literature the reflecting word is specific, and for the cinema the reflected word. Or a little in a different way: the distinction of cinematograph is in image" [4; p. 111]. Thus, the key distinction of cinema art and the literature is its "photographic nature of moving things at representation time" [6; p. 25].

The movie remains integral due to montage, so the division for frames we consider as the next research step. The frame plays a significant role, as in cinema theorician' opinion it is a certain space organization. To divide frames it is necessary to realize that every frame is a perfect picture with a clear image and meaning finding room in writer's imagination and are represented in it. M. Romm persisted, that "frames are connected according their similarity within one scene, and not according to their contrast" [7; p.197].

The shot is represented within the frame, which right separating will supplement the main artistic work idea disclosure. Using the shot we observe important details in the frame serving as emotional and psychological meaning. O. Braiko asserts: "In verbal artistic work shots are specified due to interior, landscape, and open-air shooting description and relevant writer's instructions, and space and object images emotional, intellectual and psychological meaning". [2; p. 42].

In artistic work artists are served by different shot types which help to separate work lines. So, a long shot helps to cover an interior underlining a character status and feelings; full and medium long shots help to concentrate at individual details research. The most applied is full shot.

Full shot shows an idea about a certain subject's action, as and the space covering by the angle of vision is reduced, and the image is detailed approaching images to the recipient. Examining different shots use and their interchanging helps to decode authors' ideas and proficiency of applying by artists the given cinematographic techniques. One more analysis element is recourse examining, that is a image "representation", as using the angle of vision the author's idea is changed.

The author's idea is decoded during a set-up examining, the one, in A. Tarkovsky opinion should not be regarded as an abstraction expressing "the sense of all that's happening" [8; p. 75]. Due to this cinematographic technique the author can manage the "characters' fortunes".

Not less important in poetics of cinema methodology is time examining. As the scholar N. Khrenov states, "time in a majority of cases is regarded as a means for obtaining a certain dramatic effect" [11; p. 249]. The scientist shares the opinion of the French scientist G. Debry that the time in a movie is "physical, psychological, artificial, dramatic and cinematographic thing" [11; p. 249].

Examining time category it is necessary to monitor its interdependence with the rhythm. N. Chrenov proves that the rhythm helps to press the chronologic time: "Frames rhythm encourages the illusion of space integration in the spectator's perception [11; p. 250]. A. Tarkovsky argues undoubtedly the judgment about the rhythm significance in cinematography and assigns to it the crucial role: "Rhythm is not metrical fragments interchanging, rhythm consists of a temporary pressure within the frames... [...] Rhythm is the main form creating element in cinematography, and not in frames montage" [8; p. 125].

Montage study should become the last analysis element, that is, frames' organization method. The montage summarizes the previous conclusions on the author's intention, as during images joining the author's style and his/her artistic skill are becoming visible. Studying the montage category in artistic work we make the esthetic content decoding. Any image montage creation cannot also be left without research attention, as only trough this poetics of cinema category we keep track of the way of its disclosure (emerging and establishing) and summarizing. It should also pay attention for time organization in space using the montage.

It is expected that at the final phase it is reasonable to name the montage types (after S. Eisenstein): metrical connects the frames together according to their length; rhythmic - the determining is the objects movement within the frame; tonal - based on dominant fragment sounding; overtone - tonal montage development continuing [10, 5153]. L. Kuleshov names two main montage types: slow and fast. For slow type not frequent long frames changing is typical and for the long one - frequent short frames changing.

Conclusion. So, literary scholars' works analysis showed the absence of uniform, proposed by scientists' methodology of artistic works poetics of cinema analysis in spite of expressive theme actuality. In the most of works the authors solve more local tasks: cinematographic rate rhythm of images, writer's montage thinking etc. So, it is seen that the researchers choose one artistic works aspect. Whereas due to possible cinematographic means arsenal recited by researchers, the writer's style affects on their decoding in every particular case. The common thing is that during poetics of cinema study it is important to speak about every means functional contents. Thus, the algorithm proposed is worth examining at practical material, in particular at E. Gutsal's Romance philology. 


\section{REFERENCES}

1. Braiko O. Montazh thinking in prose by Vladimir Drozd / Alexander Brayko//Word and time, 2014 (8). P. 27 - 44.

2. Braiko O. Cinematic potential of literary text: modeling of space in creativity V. Drozd / Alexander Brayko//Word and time, 2015 (10). P. 41-56

3. Gorbolys L. Cinematic arsenal of "Fireplace Cross" / Larisa Gorbolys//Word and time, 2014 (6). P. 32 - 39.

4. Kozlov L.K. Image and image: Essays on historical poetry of Soviet cinema. M.: Art, 1980. P. 288.

5. Lotman Y. Structure of the artistic text. Moscow: Art, 1970. P. 388.

6. Pokulevskaya AI Elements of the cinema in the poetry of a literary work: Dis.... Candidate filol Sciences / Anna I.
Pokulevskaya; Kirovograd State Pedagogical University named after Volodymyr Vynnychenko. Kirovograd, 2013. P. 197.

7. Romm M.I. Selected Works in 3-t. / M. I. Romm. Moscow: Art, 1982. T. 1. P. 576.

8. Tarkovsky A. The Time Takkov / Andriy Tarkovsky; Per. from Russian and the compiler N. Sobolev. Kyiv: AlterPres, 2011. P. 268.

9. Eisenstein S. Selected Works in Six Volumes / Sergey Eisenstein. T. 2. Moscow: Art, 1964. P. 600.

10. Eisenstein S. Selected Works in Six Volumes / Sergey Eisenstein. T. 3. Moscow: Art, 1964. P. 578.

11. Khrenov N. Artistic time in the film (Eisenstein, Bergman, Wells) / N. Khrenov / Rhythm, space and time in literature and art. Leningrad: Science, 1974. P. 248 - 261. 